\title{
Unilateral Hypoplasia of Lung in Association with Dilated Stomach
}

\author{
${ }^{1}$ Sangeeth Kumar Kasilingam, ${ }^{2}$ Savita Jindal
}

\begin{abstract}
Human lung growth starts as a primitive lung bud in early embryonic life and its growth is determined by various factors which occur during development. Pressure effects during intrauterine life from neighboring organs can impede the growth and lead to a hypoplastic lung. These could be due to associated congenital abnormalities of diaphragm, kidney, heart, GIT, etc. Dilated stomach is a rare association with a hypoplastic lung. We describe a case of congenital unilateral pulmonary hypoplasia in association with dilated stomach in a 25-year-old man who presented with exacerbation of bronchial asthma.
\end{abstract}

Keywords: Lung hypoplasia, Dilated stomach, Asthma.

How to cite this article: Kasilingam SK, Jindal S. Unilateral Hypoplasia of Lung in Association with Dilated Stomach. J Postgrad Med Edu Res 2014;48(1):40-42.

\section{Source of support: Nil}

Conflict of interest: None

\section{INTRODUCTION}

Arrested development of lung is classified into 3 types:

1. Agenesis which is complete absence of one or both lungs,

2. Aplasia which suppression of all but a rudimentary bronchus that ends in a blind pouch with no evidence of pulmonary vasculature or parenchyma,

3. Hypoplasia in which the gross morphology of lung is essentially unremarkable but in which there is decrease in the number or size of airways, vessels and alveoli. ${ }^{1}$ Pulmonary hypoplasia is most commonly associated with some fetal abnormality which interferes with normal development of lungs.

\section{CASE HISTORY}

A 25-year-old man presented to pulmonary medicine department of our hospital with complaints of cough, breathlessness and wheezing since 1 week. He was a tailor in a garment factory and was a nonsmoker and nonalcoholic.

\footnotetext{
${ }^{1,2}$ Assistant Professor

${ }^{1}$ Department of Pulmonary Medicine, ESIC MC and PGIMSR Bengaluru, Karnataka, India

${ }^{2}$ Department of Pulmonary Medicine, BJ Medical College Ahmedabad, Gujarat, India
}

Corresponding Author: Sangeeth Kumar Kasilingam Assistant Professor, Department of Pulmonary Medicine ESIC MC and PGIMSR, Bengaluru, Karnataka, India, Phone: 91-9241527533, e-mail: sangeethbmcmed@gmail.com
His birth history was unremarkable. He had history of bronchial asthma since 5 years for which he was on regular medication.

\section{CLINICAL EXAMINATION}

The patient was dyspneic at rest, pulse-110/min, BP-110/76 mm Hg, respiratory rate-36/min. Trachea was markedly deviated to left, Left hemithorax was smaller compared to right. Auscultation revealed extensive rales bilaterally. Heart sounds were prominent in the left anterior and midaxillary line.

\section{INVESTIGATION}

Chest X-ray showed deviation of trachea to left, smaller left hemithorax, emphysematous right lung, soft tissue opacity in left lower zone and absence of cardiac margins. Hematological investigations were within normal limits. CT thorax with oral contrast showed hypoplastic left lung with compensatory hyperinflation of right lung parenchyma, shift of mediastinum to left, raised left dome of diaphragm (Fig. 1). Moderate distension of entire stomach (Fig. 2) was also seen without any significant abnormality in gastric outlet and small bowel. PFT showed large airway obstruction with significant reversibility.

\section{DISCUSSION}

In the human embryo, development of lung starts as early as 3 weeks of embryonic life and continues into postnatal life up to early adulthood. The structural and vascular development of lung is closely related and progresses simultaneously in the human fetus. The events of antenatal growth and development of human lung have traditionally been divided into 5 stages. Each of these stages have possibilities of congenital malformation associated with abnormal lung development. The intrauterine period between 17 to 27 weeks is called pseudoglandular stage which involves formation of respiratory bronchioles, alveolar ducts, primitive alveoli, differentiation of type I and II pneumocytes and formation of alveolar capillary barrier. Congenital malformations during this period include cystic adenomatoid malformation, pulmonary sequestration, lung hypoplasia, lung cysts, congenital pulmonary lymphangiectasia and congenital diaphragmatic hernia. ${ }^{2}$ 
Hypoplasia mainly involves the whole lung; when it affects only one lobe, it is often accompanied by anomalies of ipsilateral pulmonary artery and anomalous pulmonary venous drainage. The incidence of unilateral agenesis is low. ${ }^{3}$ Hypoplasia of lung may be regarded as primary (idiopathic) or secondary when it occurs in association with environmental factors or other congenital anomalies that may be implicated in its pathogenesis. ${ }^{4,5}$ Several mechanisms have been implicated in secondary pulmonary hypoplasia including decreased hemithoracic volume, decreased pulmonary vascular perfusion, decreased fetal respiratory movements and decreased lung fields.

Most frequent abnormality associated with decreased volume of ipsilateral hemithorax is pulmonary hypoplasia. The most common cause is a space occupying mass within the pleural cavity, usually abdominal contents that have been displaced through a congenital diaphragmatic hernia. ${ }^{6,7}$ Thoracic neuroblastoma, sequestered lung, ${ }^{6}$ accessory diaphragm ${ }^{8}$ and pleural effusion ${ }^{9,10}$ have also been reported; occasionally, intra-abdominal tumors or fluid collections can be large enough to have the same effect. The importance of the space-occupying nature of the abnormal intrathoracic contents is shown by the development of pulmonary hypoplasia after the production of experimental diaphragmatic hernias in lambs. ${ }^{11}$ A variety of musculoskeletal deformities of the thoracic cage ${ }^{6,12-14}$ diaphragm ${ }^{15}$ and abdominal wall ${ }^{16}$ have also been associated with pulmonary hypoplasia; although it is likely that these abnormalities also act by reducing the size of thoracic cavity, it is possible that decreased intrauterine respiratory movements secondary to diminished chest wall compliance or decreased respiratory muscle mass may be of greater significance. ${ }^{17}$

Conditions leading to oligohydramnios such as early rupture of membranes or fetal renal insufficiency also impair development of lungs. Hypoplasia may be bilateral in thoracic dystrophies and oligohydramnios. Dilated stomach is a rare association with lung hypoplasia which

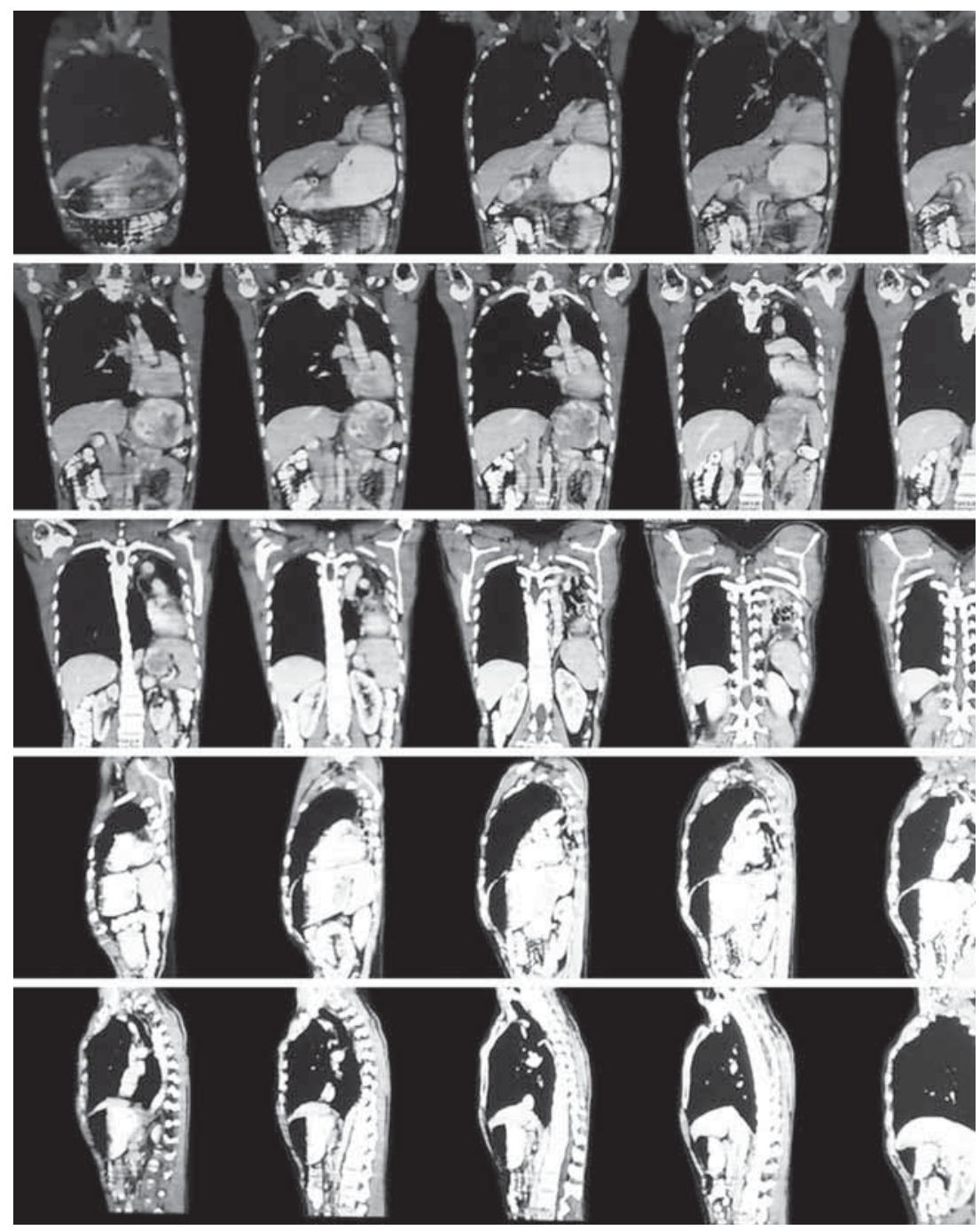

Fig. 1: Serial sections of CT chest showing hypoplastic left lung with compensatory hyperinflation of right lung, shift of mediastinum to left, raised left done of diaphragm with dilated stomach 


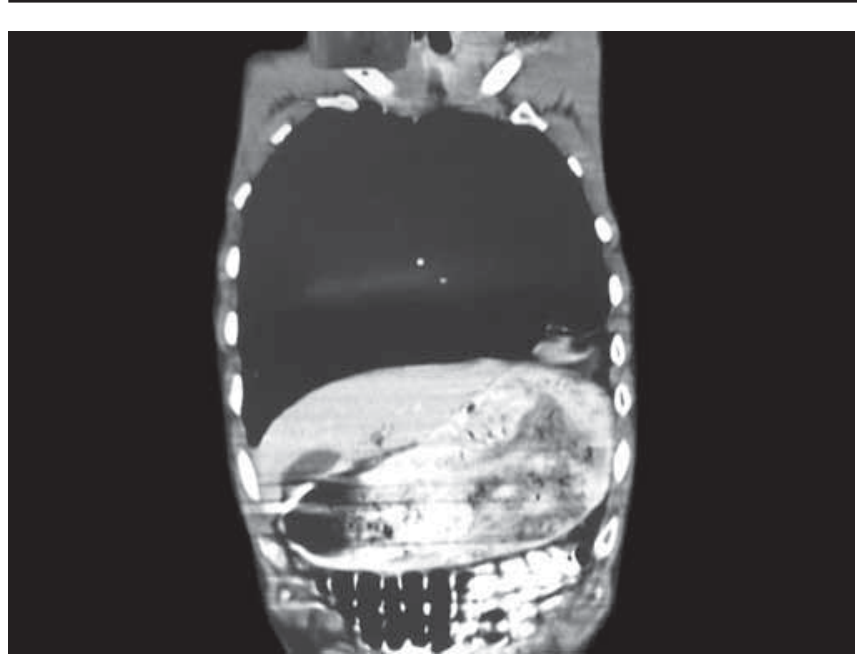

Fig. 2: Dilated stomach

could have caused pressure effect on the diaphragm and lung causing the above condition in this case. Cause of dilated stomach could not be confirmed as the patient did not have any gastrointestinal symptoms and was not willing for biopsy.

\section{REFERENCES}

1. Fraser RS, Muller NL, Colmn N, Pare PD. Developmental anomalies affecting the airways and lung parenchyma. Diagnosis of diseases of chest, 4 th ed. United States of America, Chapter 22, p 598-601.

2. Kotecha S. Lung growth for beginners. Paediatr Respir Rev 2000;1(4):308-313.

3. Maltz DL, Nadas AZ. Agenesis of lung: presentation of 8 new cases and review of literature. Paediatrics 1968;42:175.
4. Swischuk LE, Richardson CJ, Nicholas MM, et al. Bilateral pulmonary hypoplasia in the neonate. Am J Roentgenol 1979; 133:1057.

5. Hussain AN, Heggler RG. Neonatal pulmonary hypoplasia: an autopsy study of 25 cases. Pediatr Pathol 1993;13:1475.

6. Page DV, Stocker JT. Anomalies associated with pulmonary hypoplasia, Am Rev Respir Dis 1982;125:216.

7. Vanamo K. A 45-year perspective of congenital diaphragmatic hernia. Br J Surg 1996;83:1758.

8. Becmeur F, Horta P, Donato L,et al. Accessory diaphragm-review of 31 cases in the literature. Eur J Pediatr Surg 1995;5:43.

9. Landing BH. Congenital malformations and genetic disorders of the respiratory tract (larynx, trachea, bronchi and lungs): state of art. Am Rev Respir Dis 1979;120:151.

10. Dresler S. Massive pleural effusion and hypoplasia of lung accompanying extralobar pulmonary sequestration. Hum Pathol 1981;12:862.

11. deLorimier AA, Tierney DF, Parker HR. Hypoplastic lungs in fetal lambs with surgically produced congenital diaphragmatic hernia. Surgery 1967;62:12.

12. Finegold MJ, Katzew H, Genieser NB, et al. Lung structure in thoracic dystrophy. Am J Dis Child 1971;122:153.

13. Johnson VP, Keppen LD, Carpenter MS. New syndrome of spondylospinal thoracic dysostosis with multiple pterygia and arthrogryposis. Am J Med Genet 1997;69:73.

14. Thibeault DW, Pettett G, Mabry SM, et al. Osteogenesis imperfecta Type IIA and pulmonary hypoplasia with normal alveolar development. Pediatr Pulmonol 1995;20:301.

15. Goldstein JD, Reid LM. Pulmonary hypoplasia resulting from phrenic nerve agenesis and diaphragmatic amyoplasia. J Pediatr 1980;97:282.

16. Argyle JC. Pulmonary hypoplasia in infants in giant abdominal wall defects. Pediatr Pathol 1987;9:43.

17. Liggins GC, Vilos GA, Campos GA, et al. The effect of bilateral thoracoplasty on lung development in fetal sheep. J Dev Physiol 1981;3:275. 